\title{
Anatomical Detail and Accuracy of the Pernkopf Atlas and Examples of Clinical Impact
}

\author{
Anne Agur, Ph.D.
}

The high fidelity anatomical structural detail seen in the Pernkopf atlas remains unmatched in other references, including surgical anatomy atlases. An example of serial dissection illustrations are examined herein, in relation to an anatomically based clinical question. The question is about radiofrequency nerve ablation, an image-guided procedure that provides a non-opioid alternative to treat joint pain. To perform these imageguided procedures effectively, the location and course of the nerve(s) being targeted is very important. Although the patient had good pain relief, the clinician was concerned about the patient's loss of sensation around the anus following an ablation procedure of the nerves innervating the sacroiliac joint, and asked for more information about the clunial nerves and their relevance to this procedure. The anatomical illustrations in the Pernkopf atlas are highly detailed and drawn from serially dissected specimens from the skin superficially to the emergence of the nerves from the intervertebral and posterior sacral foramina.

Tracing the clunial nerves through five serial illustrations provided the necessary anatomical insight required to answer this clinical question for development of the ablation procedure. This atlas could play a significant role in educating future clinicians and surgeons and provide answers to anatomically related clinical quandaries. However, the atlas must always be used by first acknowledging its origins and history.

OPEN ACCESS

To demonstrate the unparalleled anatomical detail and accuracy of the Pernkopf atlas, I will share with you an example of an anatomically based clinical question that was explored, and ultimately answered and explained, using illustrations from this book.

The example involves radiofrequency nerve ablation, an image-guided procedure that provides a non-opioid alternative to treat joint pain. To perform these image guided procedures the location and course of the nerve(s) being targeted is very important. The question arose when we were conducting the anatomy laboratory component of a radiofrequency nerve ablation procedures course at the station focusing on the nerve supply of the sacroiliac joint. The sacroiliac joints link the trunk and the lower limb. These joints are located between the right and left hip bones and the sacrum (Figure 1). The posterior part of the joint is ligamentous consisting of the posterior and interosseous sacroiliac ligaments. The clinician asked, "My patient had good pain relief following a radiofrequency ablation procedure of the nerves innervating the sacroiliac joint, but lost some sensation around the area of the anus. Can you please provide me with more information about the clunial nerves and their relevance to this procedure?"

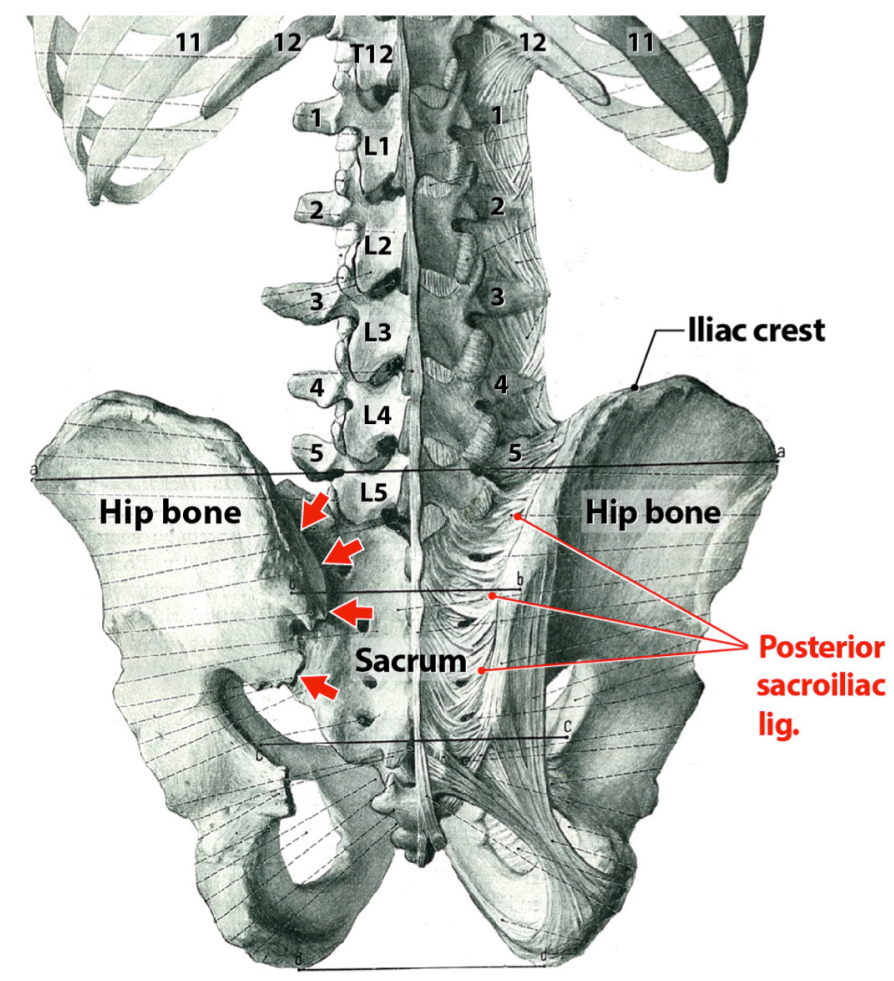

Figure 1. Location of sacroiliac joint (red arrows), posterior view. 11th and 12th ribs $(11,12) ; 12$ th thoracic vertebra (T12); 1 st to 5th lumbar vertebrae (L1-L5); paired transverse processes of lumbar vertebrae (1-5). From Pernkopf, 1943, II. Band: Bauch, Becken und Beckengliedmaße, Abb. 49. Image credit: MUW-Josephinum. 
In the Pernkopf atlas the clunial nerves, as dissected in situ, are depicted at a level of detail, not seen in other atlases. There are three groups of clunial nerves: superior, middle and inferior. This discussion will focus on the superior and middle clunial nerves. The illustrations are all from the 1943 edition of Eduard Pernkopf's Topographische Anatomie des Menschen.

In order to provide anatomical insight into this clinical question, we need to be able to trace these nerves using serial (layered) dissection. The illustrations in the Pernkopf atlas are detailed and drawn from serially dissected specimens from the skin superficially to the level of the emergence of the nerves from the vertebral column deeply. The following series of exquisitely rendered images from the Pernkopf atlas, along with a focused description of the superior and middle clunial nerves, will illustrate the relevant anatomy sequentially from superficial to deep.
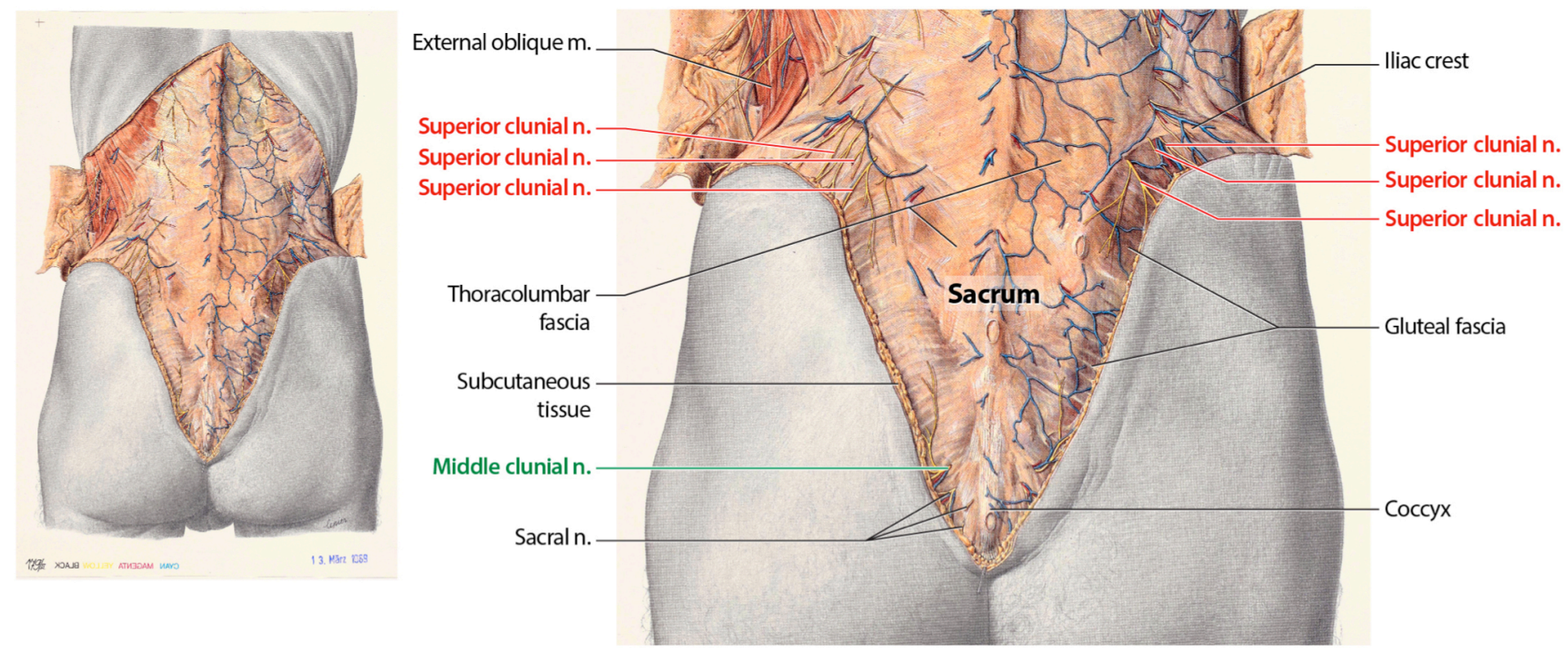

Figure 2. Serial dissection I: Superficial dissection of the lower back and gluteal region, posterior view. From Pernkopf, 1943, II. Band: Bauch, Becken und Beckengliedmaße, Abb. 25. Image credit: MUW-Andruck-179ll-Seite 1.

Figure 2 is a superficial dissection of the lower back and gluteal region. Small nerves and vessels can be seen penetrating the deep fascia of the back and gluteal region and coursing in the fatty subcutaneous tissue that underlies the skin. These nerves supply sensation to the skin. The superior clunial nerves, branches of the posterior rami of spinal nerves L1-3, can be seen piercing the deep fascia at the level of the iliac crest and coursing into the subcutaneous tissue to terminate in the skin of the superolateral gluteal region.
More inferiorly, at the level of the inferior sacrum and coccyx, the middle clunial nerves emerge through the gluteal fascia, covering the gluteus maximus muscle. Branches of the middle clunial nerves can be seen coursing inferiorly and entering the subcutaneous tissue. 

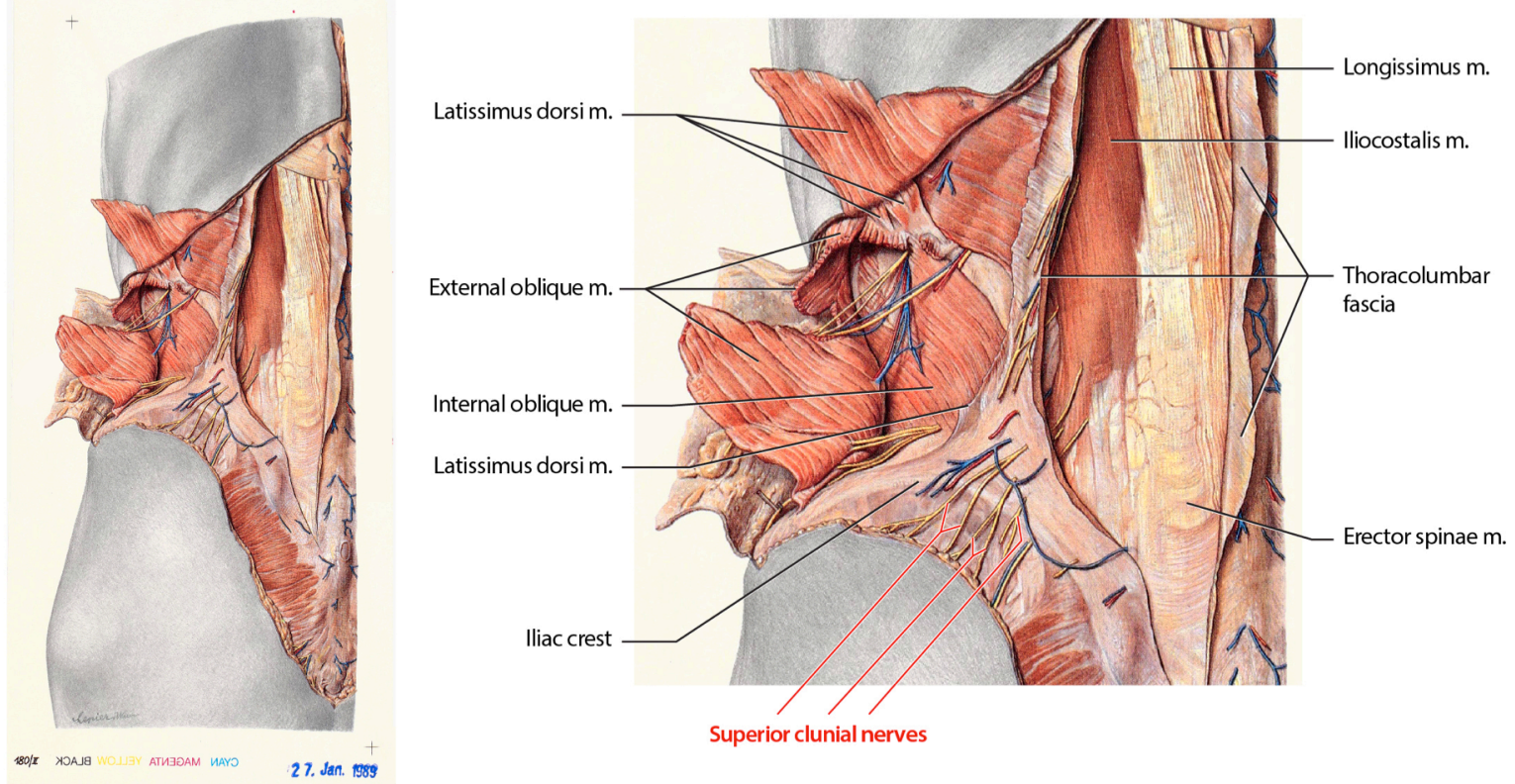

Figure 3. Serial dissection II: The external oblique muscle and thoracolumbar fascia have been reflected, posterior view. From Pernkopf, 1943, II. Band: Bauch, Becken und Beckengliedmaße, Abb. 26. Image credit: MUW-Andruck-180ll-Seite 1.

Figure 3 is a deeper dissection focusing on the superior clunial nerves. Note that the thoracolumbar fascia over the lower back has been reflected to reveal the erector spinae muscle group. The erector spinae are the more superficial of two groups of deep back muscles, and consists of the iliocostalis longissimus and spinalis muscles. The superior clunial nerves can be seen emerging from the lateral aspect of the erector spinae, penetrating the thoracolumbar fascia (reflected) and crossing over the iliac crest as shown in Figure 2.
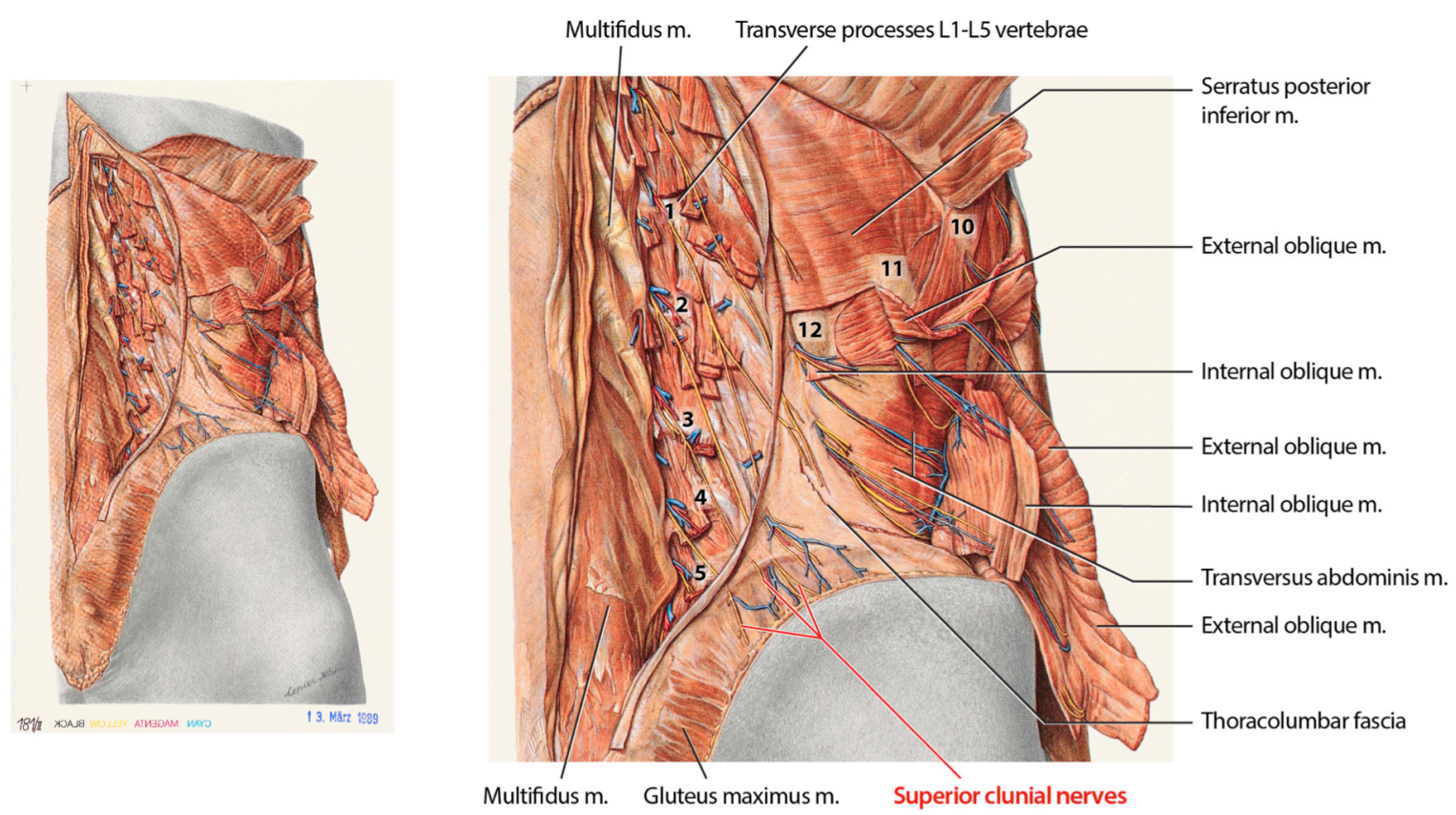

Figure 4. Serial dissection III: The erector spinae muscle group has been removed inferiorly, posterior view. 10th, 11th and 12th ribs (10,11, 12); transverse processes of lumbar vertebrae (1-5). From Pernkopf, 1943, II. Band: Bauch, Becken und Beckengliedmaße, Abb. 26. Image credit: MUW-Andruck-181ll-Seite 1. 
Figure 4 shows the course of the superior clunial nerves following removal of the erector spinae muscle group. The multifidus muscle has been exposed. It consists of a large belly inferiorly and oblique muscular slips superiorly. The multifidus is part of the transversospinalis muscles, the deeper group of the two groups of deep back muscles. The superior clunial nerves can now be seen emerging at the lateral border of the multifidus muscle and traveling deep to the area previously occupied by the erector spinae muscles depicted in Figure 3.
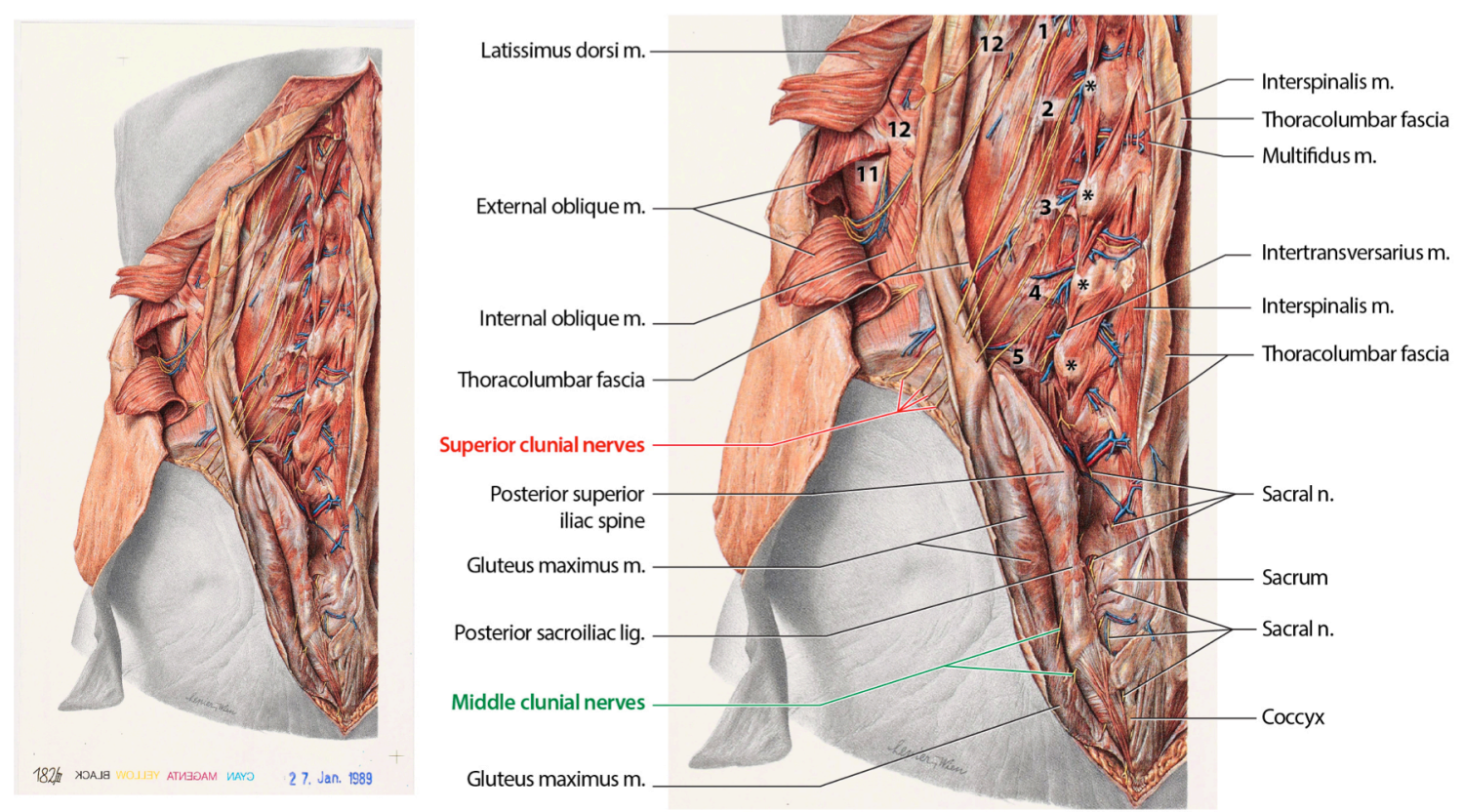

Figure 5. Serial dissection IV: The deep fascia is reflected to reveal the transverse processes and zygapophysial (facet) joints (*), posterior view. From Pernkopf, 1943, II. Band: Bauch, Becken und Beckengliedmaße, Abb. 29. Image credit: MUW-Andruck-182ll-Seite 1.
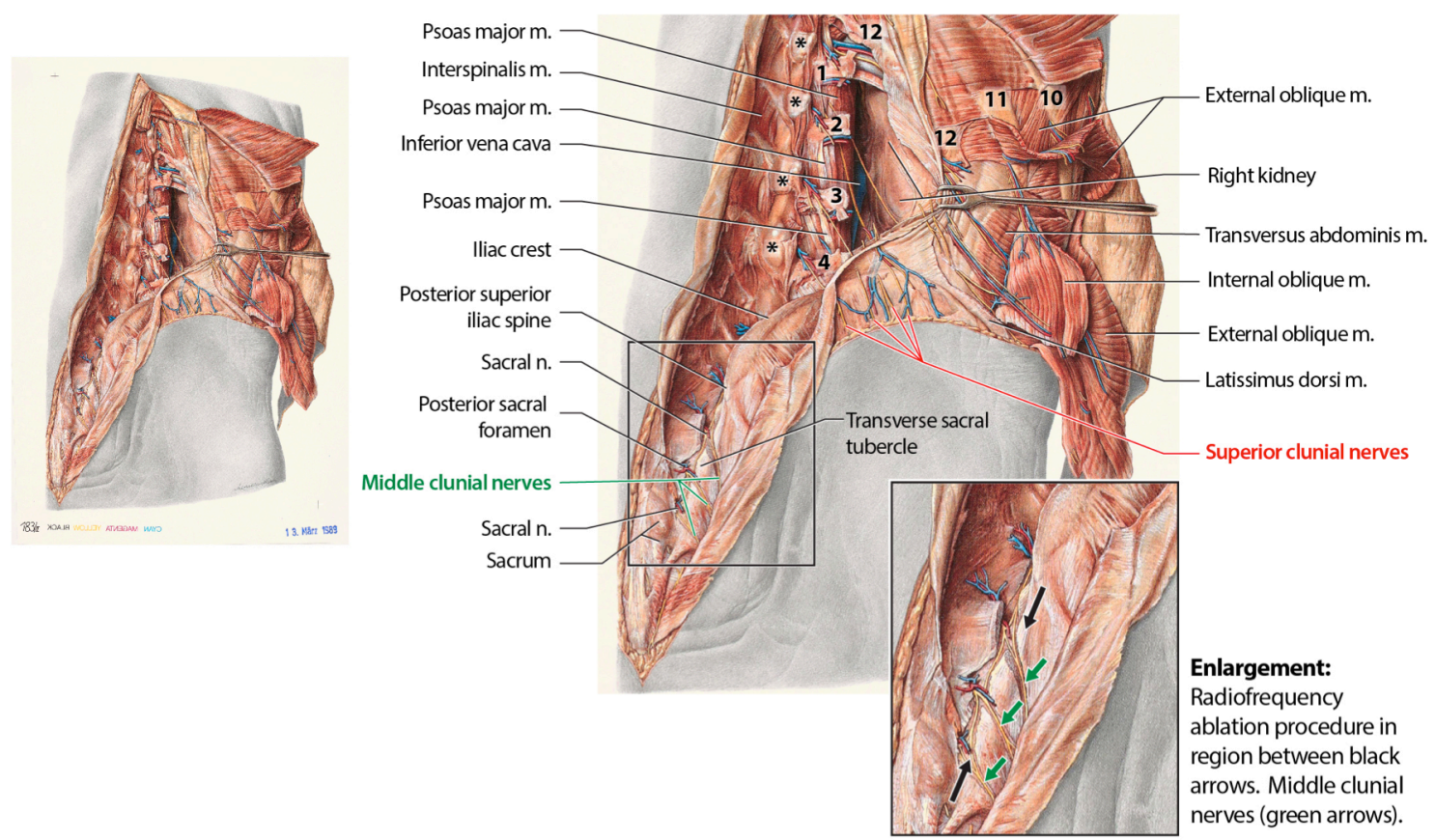

Figure 6. Serial dissection V: Deepest dissection showing course of superior and middle clunial nerves relative to bony landmarks of the lumbar spine and sacrum, posterolateral view. 10th, 11th and 12th ribs $(10,11,12)$; transverse processes of lumbar vertebrae (1-4); zygapophysial (facet) joints (*) between lumbar vertebra. From Pernkopf, 1943, II. Band: Bauch, Becken und Beckengliedmaße, Abb. 29. Image credit: MUW-Andruck-183ll-Seite 1. 
In Figure 5, the next level of serial dissection, the fascia covering the transversospinalis muscle group has been removed revealing the interspinalis and intertransversarius muscles arising from the transverse processes of the lumbar vertebrae and the sacrum. The superior clunial nerves can be seen emerging between the transverse and spinous processes of the lumbar vertebrae. This is close to the origin of these nerves from the posterior rami of the spinal nerves that arise from the spinal cord. The superior clunial nerves can be seen coursing inferolaterally through the transversospinalis muscles to reach the reflected thoracolumbar fascia. The middle clunial nerves are exposed as they course through the deep fascia overlying the sacrum.

Figure 6 is a posterolateral view of the dissection in Figure 5, with further exposure of the lumbar spine. The transverse processes of the lumbar vertebrae are more completely exposed by removal of most of the small remaining muscles that attach to their surfaces, and the quadratus lumborum muscles. The fascia surrounding the right kidney is visible. Also, the zygapophysial (facet) joints between the lumbar vertebrae have been demarcated.

This dissection enables visualization of the course and relationship of the superior clunial nerves to the zygapophysial joints and transverse processes of the lumbar vertebrae. The middle clunial nerves can be seen coursing inferolateral from the posterior sacral foramina, passing inferior to the transverse sacral tubercles into the deep fascia. The region of the sacroiliac radiofrequency ablation procedure is located between the black arrows, seen in Figure 6. Note the close proximity of the middle clunial nerves to this region, indicating the possibility that these nerves could be affected by the procedure.

This series of five dissections clarifies the course and location of the superior and middle clunial nerves to aid in understanding their possible involvement in clinical scenarios.

The level of high fidelity anatomical structural detail seen in the Pernkopf atlas is not present in other references, including surgical anatomy atlases and books. This atlas could play a significant role in educating future clinicians and surgeons and provide answers to anatomically related clinical quandaries.
However, in the clinical community, knowledge of the Pernkopf atlas and its contents are lacking.

Whenever I have shown this atlas to students and clinicians, I have always explained the origin and history of the atlas. The Pernkopf atlas is an irreplaceable resource. However, the users must convey its origins to future generations of learners. The history of the Pernkopf atlas must be known to honor and memorialize the victims of the Holocaust.

\section{Reference}

Pernkopf, Eduard. 1943. Topographische Anatomie des Menschen: Lehrbuch und Atlas der regionarstratigraphischen Praparation. Berlin, Germany: Urban \& Schwarzenberg.

\section{About the Author}

Prof. Anne Agur Ph.D., Professor, Division of Anatomy, Department of Surgery, Temerty Faculty of Medicine, University of Toronto, teaches clinical anatomy, histology, neuroanatomy and embryology. She has been a teacher and researcher in the Division for more than 40 years with a primary research interest in clinically applied normal vs. pathological structure and function of the musculoskeletal system including joints, musculotendinous architecture, innervation patterns and pain-generating mechanisms. Prof. Agur is the coauthor of Grant's Atlas of Anatomy, Essential Clinical Anatomy, and Clinically Oriented Anatomy. In 2018, she was recognized with an award from the American Association of Clinical Anatomists" and in April 2019 she received the Henry Gray/Elsevier Distinguished Educator Award from the American Association of Anatomists.

\section{Anne Agur, Ph.D.}

Professor, Division of Anatomy, Department of Surgery,

Temerty Faculty of Medicine, University of Toronto Contact: anne.agur@,utoronto.ca 


\section{Licensing}

The author has chosen to license this content under a Creative Commons Attribution, NonCommercial, NoDerivatives 4.0 International License.

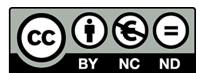

Authorization for publication of images from Pernkopf's atlas has been granted for use in this article only. The atlas images must remain within the context of this article for open-access, scholarship and educational use. The atlas images in this article may not be removed from this article, nor reproduced, nor distributed, outside of the context of this article, for scholarly, education or commercial purposes, without the expressed permission of the Josephinum.

\section{Image Credits}

The Journal of Biocommunication wishes to thank the Josephinum and the Medical University of Vienna for approving the publication of Pernkopf atlas images that are used within this Special Issue. These images may appear on the cover, in the Table of Contents, and as figures within articles and are acknowledged with the following image credit:

Josephinum - Ethik, Sammlungen und Geschichte der Medizin, MedUni Wien

\section{Josephinum - Ethics, Collections and History of} Medicine, MedUni Vienna

\section{Conflict of Interest Statement}

The Journal of Biocommunication Management Board and Editors believe that transparency in academic research is essential. Our JBC authors are now required to disclose any possible conflict of interest when submitting a manuscript. In accordance with the Journal of Biocommunication's editorial policy, no potential conflict of interest has been reported or declared by this author. 